Leila Bitencourt Reis da Silva ${ }^{1}$ Roberto Henrique Pôrto Nogueira ${ }^{1}$

\title{
A IGUALDADE DEMOCRÁTICA NA RELAÇÃO PACIENTE-PSIQUIATRA COMO MEIO PARA $O$ EXERCÍCIO DA LIBERDADE PARA ALÉM DA ADESÃO AO TRATAMENTO*
}

Democratic equality in the patient / psychiatrist relationship as an instrument for the exercise of freedom beyond treatment adherence

${ }^{1}$ Universidade Federal de Ouro Preto. Ouro Preto/MG, Brasil.

Correspondência: Leila Bitencourt Reis da Silva. E-mail: leilareis091@gmail.com

Recebido: 31/10/2017. Revisão: 16/04/2018. Nova revisão: 08/07/2018. Aprovado: 10/09/2018.

\footnotetext{
*Fontes de financiamento: Coordenação de Aperfeiçoamento de Pessoal de Nível Superior (Capes) e Auxílio Pesquisador da Universidade Federal de Ouro Preto, 2017.
} 


\section{RESUMO}

O tratamento psiquiátrico pode contribuir para a desconsideração do paciente como sujeito de direito e tem o potencial de estimular juízos degradantes de sua capacidade. O objetivo do trabalho, que adota processos teóricos de estudo jurídico-descritivo e jurídico-propositivo, é identificar medidas práticas para a adesão e a condução terapêuticas adequadas, que viabilizem a igualdade democrática cunhada na teoria de Elizabeth Anderson. O estudo evidencia que a necessidade de proteção do paciente deve afastar-se de um recorrente efeito reverso, qual seja, sua inferiorização. Cabe, assim, criar meios para a emersão de sua volição, ainda que inferida, quanto à medida considerada adequada no tratamento psiquiátrico, com repercussões oriundas do movimento antimanicomial e do panorama da teoria das incapacidades transformado pelo Estatuto da Pessoa com Deficiência. Como resultado, propõe-se que a opção pelas medidas de cuidado, independentemente da incapacidade do paciente e diante dos parâmetros normativos expostos, seja privilegiada e informada pelo psiquiatra na fase de acesso, de acolhimento ou de acompanhamento. O estudo é importante porque colabora para a concretização do respeito à dignidade do paciente. Nesse tocante, viabiliza-se o exercício da liberdade para além da mera adesão ao tratamento psiquiátrico.

\section{Palavras-Chave}

Igualdade Democrática; Medidas de Cuidado; Novos Direitos; Relação Médico-Paciente; Tratamento Psiquiátrico.

\section{ABSTRACT}

Psychiatric treatment might contribute to the disregard of the patient as a person, and might stimulate degrading judgments of their capacity. The objective of the paper, based on juridical-descriptive and juridical-propositional theoretical processes, is to identify practical measures for the adequate adherence and therapeutic management, to enable democratic equality as coined in Elizabeth Anderson's theory. The study shows that the need for protecting the patient must stir away from a recurring reverse effect: disparagement. Therefore, facilitating the emergence of their volition is appropriate, even if inferred, regarding the adequate strategy of psychiatric treatment, with repercussions stemming from the anti-asylum movement and from the panorama of disabilities theory transformed by Brazil's Disability Inclusion Act. As a result it is proposed that the option for caring measures, independently from the patient's disability and in view of normative parameters, should be privileged and informed by the psychiatrist in the phase of access, sheltering or follow up. The study is important because it helps to respect the patient's dignity. And so, the exercise of freedom becomes feasible beyond the mere adherence to psychiatric treatment.

\section{Keywords}

Democratic Equality; Strategies of Care; New Rights; Doctor / Patient Relationship; Psychiatric Treatment. 


\section{Introdução}

Desde o Juramento de Hipócrates, no século V a.C., a ciência médica deu um grande salto no que diz respeito aos contornos da relação médico-paciente. A concepção paternalista de prática médica e de objetificação do paciente ${ }^{1}$ tem perdido lugar para uma relação com enfoque no consentimento participativo do sujeito a ser submetido a tratamento médico. Ganha relevo o dever profissional de prestar informações mais amplas. Novos procedimentos viabilizados pela tecnologia aumentam os riscos, especialmente quando são de caráter invasivo ${ }^{2}$.

A metodologia de estudo teórico é, assim, jurídico-descritiva e jurídico-propositiva. Para tanto, lança-se mão do uso de fontes secundárias (livros, artigos, dissertações e teses), por meio de uma revisão de literatura sobre o tema.

O objetivo do trabalho é identificar medidas práticas para a adesão e a condução terapêuticas adequadas, que viabilizem a igualdade democrática cunhada na teoria de Elizabeth Anderson ${ }^{3}$. Intenta-se apontar proposições que se aproximem de concepções de direitos de igualdade e liberdade na adesão e condução terapêuticas, especialmente no campo da Psiquiatria. A despeito de a relevância das medidas de cuidado despontarem na prática da psiquiatria forense, elas estão disponíveis à prática médica psiquiátrica geral, tendo em vista seu potencial de instituir um catálogo plural, promotor de um novo cenário jurídico de maior espaço às capacidades e apto a ser implementado com a colaboração do profissional médico.

Como resultado, a aptidão do paciente pode ser privilegiada por meio da adoção de práticas médicas dialógicas possíveis de ser alcançadas mediante a aplicação de medidas de cuidado independentemente da incapacidade do paciente. Somado a isso, propõe-se o aprimoramento dos meios de comunicação, seja com o auxílio de tecnologias, seja pela reformulação de processos de formação profissional, especialmente no que toca à semiologia. Destaca-se que o foco das reflexões é a relação entre as medidas de cuidado e as ações em prol da promoção dialógica nas relações entre psiquiatras e pacientes, no panorama das normativas principiológicas do movimento refletido na Lei Antimanicomial ${ }^{4}$ e das recentes mudanças

\footnotetext{
${ }^{1}$ Sobre esse neologismo, ver STANCIOLI, Brunello Souza. Relação Jurídica médico-paciente. Belo Horizonte: Del Rey, 2004. p. 25.

${ }^{2}$ TEIXEIRA, Ivan Lobato. Capacidade e consentimento na relação médico/paciente. 2009. 210f. Dissertação (Mestrado) - Programa de Pós-Graduação em Direito da Faculdade de Direito da Universidade de São Paulo, São Paulo, 2012. p. 68-71, Disponível em: http://www.teses.usp.br/teses/disponíveis/2/2131/tde07052010-085547/. Acesso em: 13 out. 2012.

${ }^{3}$ ANDERSON, Elizabeth S. Qual é o sentido da igualdade? Revista Brasileira de Ciência Política, BrasíliaDF, n. 15, p. 165, set./dez. 2014. http://dx.doi.org/10.1590/0103-335220141507. Disponível em: http:// periodicos.unb.br/index.php/rbcp/article/view/13080. Acesso em: 13 jun. 2017.

${ }^{4}$ BRASIL. Lei $n$. 10.216, de 06 de abril de 2001. Dispõe sobre a proteção e os direitos das pessoas portadoras de transtornos mentais e redireciona o modelo assistencial em saúde mental. Brasília: Disponível em: http://www.planalto.gov.br/ccivil_03/leis/leis_2001/I10216.htm. Acesso em: 29 jun. 2017.
} 
trazidas pelo Estatuto da Pessoa com Deficiência ${ }^{5}$ à teoria das capacidades. Aqui, considerando a novidade no campo do Direito, a contribuição às comunidades médica e jurídica decorre, antes, da exposição, a partir da concepção da igualdade democrática, da necessidade de buscar uma concepção plural e não taxativa das medidas de cuidado.

Espera-se lançar luz sobre a maior consideração da pessoa e de sua competência para exercício do poder de decisão sobre seu tratamento, por meio da possível identificação de medidas de cuidado menos categorizadas e, portanto, mais plurais. Pretende-se, em última instância, tratar a igualdade para além da questão numérica na integração de pessoas em polos da relação jurídica; e a liberdade para além da mera possibilidade de adesão ao tratamento. Logo, essa abordagem há de desenhar mecanismos disponíveis à prática médica que assegurem juridicamente a prerrogativa, que se pretende mais efetiva, de permanência do paciente na relação e de legitimação do condutor (médico) do processo decisório.

\section{Igualdade democrática na relação paciente-psiquiatra}

A relação entre o médico e o paciente é complexa no que tange ao equilíbrio do poder de influência acerca das decisões que permeiam o tratamento. Ainda que haja opção acerca de qual profissional será contratado, na maioria das vezes as circunstâncias de necessidade da contratação acabam por mitigar a autonomia do paciente, no que concerne tanto à escolha da terapêutica quanto à posterior condução. Ademais, é nesse contexto que o profissional presta dados e informações de natureza técnica, que são a base para o consentimento do paciente ${ }^{6}$.

Essa dinâmica não é diferente na Psiquiatria, em que o médico deve buscar ser compreendido e, por certo, adotar linguagem clara e de simples intelecção, com o fito de alcançar o entendimento. Se é verdade que aspectos técnicos são complexos para os que dominam as linguagens específicas, é consectário lógico que tal intercompreensão pelo paciente, além de complexa, apresenta-se improvável. Afinal, o paciente tende a ser leigo.

Imersa nessa questão entre o psiquiatra e o paciente, tem-se a discussão sobre a igualdade, haja vista que o consentimento, apesar da complexidade na formação de convicções, deve edificar-se em juízos conscientemente construídos a partir das variáveis médicas descortinadas. Para tanto, espera-se alguma igualdade no exercício do poder de decisão do paciente, ainda que este seja, em princípio, vulnerável.

\footnotetext{
${ }^{5}$ BRASIL. Lei n. 13.146, de 06 de julho de 2015. Institui a Lei Brasileira de Inclusão da Pessoa com Deficiência (Estatuto da Pessoa com Deficiência). Disponivel em: http://www.planalto.gov.br/ccivil_03/_ato20152018/2015/lei//13146.htm. Acesso em: 01 jul. 2017

${ }^{6}$ NOGUEIRA, Roberto Henrique Porto. Prescrição off label de medicamentos, ilicitude e responsabilidade civil do médico. Belo Horizonte: Ed. PUC Minas, 2017. p. 188.
} 
Este ensaio ocupa-se, por opção metodológica, da igualdade articulada por Elizabeth Anderson ${ }^{7}$. Apesar de suas palavras terem sido discorridas em trabalho que almeja analisar o mercado em sentido amplo e a relação do sujeito com o Estado, há substrato suficiente para o esforço de abstração, a partir dos escritos da autora, de ideias que elucidem o tratamento da pessoa humana na perspectiva da igualdade, no que concerne a sua consideração como pessoa capaz de reger decisões a respeito de sua própria vida. Acredita-se que esse viés mostra-se mais adequado aos estudos da relação psiquiatra-paciente.

Partindo de críticas às teorias igualitaristas, Anderson registra que a compreensão liberal de igualdade, que ostenta o objetivo de neutralidade quanto às concepções de bem, acaba por incentivar a irresponsabilidade. Aponta que o igualitarismo, ao pretender identificar e corrigir as injustiças por meio da atuação de agentes externos, pode invadir a privacidade da pessoa ${ }^{8}$.

Vale destacar que se entende igualitarismo como

posição normativa segundo a qual uma sociedade democrática justa é aquela comprometida com a garantia de direitos básicos iguais e uma parcela equitativa dos recursos sociais escassos renda, riqueza e oportunidades educacionais e ocupacionais - a todos os seus cidadãos. A ideia central desse ideal normativo se apoia em uma divisão moral de trabalho entre a sociedade e seus membros individuais. À sociedade - aos cidadãos como um corpo coletivo - cabe a responsabilidade de dar forma a uma estrutura institucional que propicie aqueles direitos e oportunidades para todos, "sem distinção de qualquer tipo, tais como raça, etnia, sexo ou religião" (para fazer uso da frase que quase invariavelmente aparece nos artigos iniciais das declarações de direitos); aos cidadãos individualmente, cabe decidir que uso farão em suas vidas desses recursos institucionalmente garantidos ${ }^{9}$.

Da mesma forma, essa invasão de privacidade pode acontecer na relação entre o paciente e o psiquiatra, caso decisões sobre o tratamento sejam tomadas sem que o interessado tenha compreensão suficiente das nuances dessa atuação.

Aceitos, por hipótese, os vetores de igualdade instituídos por Anderson, merece destaque o tracejamento dialógico das diretrizes da relação para além da consolidada recomendação de obtenção, pelo profissional médico, do consentimento livre e esclarecido. Isso significa que o foco do fomento à igualdade deve posicionar-se

\footnotetext{
${ }^{7}$ ANDERSON, Elizabeth S. op. cit..

${ }^{8}$ Id. Ibid., p. 163-164.

${ }^{9}$ DE VITA, Álvaro. Liberalismo igualitário e multiculturalismo. Lua Nova, São Paulo, n. 55-56, p. 05, 2002. http://dx.doi.org/10.1590/S0102-64452002000100001. Disponivel em: http://www.scielo.br/scielo. php?script=sci_arttext\&pid=S0102-64452002000100001\&lng=en\&nrm=iso. Acesso em: 02 jun. 2017.
} 
no reequilíbrio entre os envolvidos, entendido como a busca de poderes menos desproporcionais entre as pessoas integrantes da relação, sob pena de o paciente seguir apenas formalmente igual - algo pouco admissível em uma comunidade que se pretenda democrática do ponto de vista do reconhecimento, da distribuição de recursos e da ocupação de posições jurídicas. Em todo caso, cabe frisar que a presente conjectura não se trata de discussão sobre o direito ao acesso a serviços de saúde, e sim sobre o contexto de prestação desses serviços considerando-se as peculiaridades da relação, que não devem resvalar na limitação da vontade do paciente.

A autora adverte para o fato de que a igualdade não democrática é desprovida de potencial para combater os desequilíbrios existentes nas relações entre as pessoas, pois considera que as desigualdades têm origens naturais. Nesse sentido, acaba por admitir a prevalência de um sujeito em detrimento do outro, bem como dá margem à ingerência na liberdade de agir daquele que se pretende tutelar. É a partir da concepção de uma pessoa considerada naturalmente desafortunada que a autora constrói a ideia de juízos degradantes de valor, ao explicar que, por meio dessa noção de igualdade, ofende-se o direito à liberdade porque não se busca "respeitar e [se] preocupar igualmente com todos os cidadãos"10.

Nesse rumo, a teoria da igualdade não democrática, criticada pela autora, pode servir de fundamento para uma intervenção estatal nas relações privadas, nos moldes paternalistas, sob o pretexto da busca pela igualdade. Ademais, ao classificar, ex ante, pessoas em categorias - como a dos afortunados (com habilidades, saberes e riquezas) e a dos desafortunados -, tal perspectiva promove a inferiorização de uma pessoa em face de outra. A categorização inicia a formação de "juízos degradantes e invasivos sobre as capacidades das pessoas de exercer a responsabilidade, pois efetivamente lhes dita os usos apropriados de sua liberdade"11.

E foi essa visão paternalista que a relação médico-paciente sustentou até o século XIX, seja na potencialização do papel do profissional, em detrimento do paciente, para a definição do "melhor" ou para "o seu bem"; seja na consideração do paciente como pessoa hipervulnerável, o que implica exclusão de possibilidades de manifestação e de participação.

Nesse ponto, pode-se iluminar a relação entre médico e paciente com o que Anderson denomina "igualdade democrática". A expressão reporta um arquétipo que objetiva construir a igualdade por meio da premissa básica do respeito igual às pessoas, para possibilitar que elas mesmas, ao exercerem suas liberdades, definam o que é melhor para que seja atingido o equilíbrio em certa relação na qual fica constatada sua fragilidade ou vulnerabilidade.

${ }^{10}$ DE VITA, Álvaro. Liberalismo igualitário e multiculturalismo. op. cit., p. 165.

${ }^{11}$ Id. Ibid., p. 167. 
Para essa matriz teórica, os próprios cidadãos devem reivindicar seus direitos com fundamento em sua igualdade, rejeitando o argumento de que deveriam ser tutelados por serem considerados inferiores aos outros. Logo, defende o exercício da liberdade fundamentado na igualdade entre as pessoas, sendo descabida a eventual intenção de outrem de impor o que deve ser feito. Nessa visão de igualdade, espera-se que a pessoas tenham iguais oportunidades de tomada de decisões, da forma que julgarem melhor para si mesmas. A autora aponta para o problema que se revela quando da desconsideração das concepções individuais de bem-estar ou quando da imposição da vontade de uma maioria. Ademais, exigir que os cidadãos apresentem evidências de inferioridade pessoal para obter ajuda de um terceiro no caso, o Estado - é reduzi-los como pessoa humana, ou seja, é fazê-los rastejarem por essa ajuda ${ }^{12}$.

Significa que protocolos consolidados pela comunidade médica não impedem que o profissional seja sensível ao arcabouço de variáveis que envolvam a decisão sobre conduta terapêutica. Além disso, é ideal que seja dada ao paciente a oportunidade de conhecer os fundamentos da opção por determinada conduta, para decidir aderir a ela ou não.

A partir disso, cabe sustentar a necessidade de implementação de dialogicidade na relação médico-paciente. Vale dizer que não se deve intervir apenas em prol de um equilíbrio de influência nas decisões com fundamento na consideração, ex ante, do paciente como pessoa a ser protegida. A ideia de uma relação dialógica, nesse caso, somente comporta as premissas da linha democrática, na qual a pessoa - no caso, o paciente - deve ter condições suficientes para ser protagonista de suas próprias decisões no tratamento psiquiátrico. É por meio dessa concepção que o igualitarismo promove a humanidade nas relações desequilibradas e se concretiza de modo a respeitar a diversidade entre as pessoas, promovendo a autonomia na escolha do próprio destino. Para tanto, a igualdade deve ser propulsora de arranjos institucionais que estejam preparados para lidar com a diversidade, de forma que todos sejam mutuamente beneficiados. Não se trata, assim, de uma igualdade que encare a diversidade como algo negativo, a ser formatada por meio de hierarquia que divida inferiores e superiores ${ }^{13}$.

Um dos maiores desafios da medicina atual é o de potencializar a autonomia da pessoa submetida ao tratamento para além da busca pela cura médico-biológica. Por isso, desponta a importância de que o paciente tenha uma visão minimamente autêntica sobre a saúde, o transtorno, o sofrimento, o diagnóstico, o prognóstico e a terapêutica, ou seja, que tenha ciência e exerça sua

\footnotetext{
${ }^{12}$ DE VITA, Álvaro. Liberalismo igualitário e multiculturalismo. op. cit., p. 185.

${ }^{13}$ Id. Ibid., p. 189.
} 
prerrogativa de determinar os rumos da decisão $0^{14}$. Essa decisão é, certamente, tomada no âmbito da relação entre psiquiatra e paciente.

Para Anderson, igualdade democrática consiste no próprio exercício da cidadania, no sentido de que esta não trata somente da ação da pessoa como agente político - votar em seus representantes e pleitear ações do governo -, pois também abrange a participação na sociedade civil em condições de igualdade, extrapolando as questões burocráticas estatais. Envolve, assim, a atuação do sujeito em vários ambientes, inclusive em espaços de uso público, entre os quais estão os hospitais. A forma como se trata o desequilibrio de saberes na relação conecta-se diretamente com a promoção da cidadania do paciente. Além disso, o poder de escolha efetivo de meios que viabilizem a existência biológica é requisito para a concretização do ser humano, visto que propicia

o conhecimento das próprias circunstâncias e opções, a capacidade de deliberar sobre meios e fins, condições psicológicas de autonomia, incluindo a autoconfiança para pensar e julgar por conta própria, liberdade de pensamento e movimento ${ }^{15}$.

Para tanto, é necessário que se promova a responsabilidade pessoal oferecendo-se o mínimo suporte às escolhas que afaste a realização de juízos do que deve ou não ser feito, bem como disponibilizando-se oportunidades e liberdade para que haja uma verdadeira escolha. É a liberdade de escolher, em igualdade dentro da diversidade assegurada a todos, que garante igualdade democrática. Essa sistemática implica, assim, um agir responsável e traz à tona a necessidade da existência de "opções reais, consciência dessas opções, competências deliberativas e a autoestima necessária para confiar no próprio juízo"16. Para tanto, a orientação, a informação e a educação devem ser promovidas, pois são as bases para essa escolha com lastro na autoconfiança e autoestima ${ }^{17}$.

Logo, a literatura já questiona com pertinência a possibilidade, em contextos psiquiátricos, de haver admissão de intervalos de lucidez ${ }^{18}$. Aqui, diante das lições de Anderson e na intenção de preservar o espaço à construção da pessoalidade sem pré-categorizações, ainda mais apropriado é apontar, na prática médica, intervalos de loucura para admitir, em regra e na esteira das premissas do Estatuto da Pessoa com Deficiência (e respectiva presunção de capacidade), a lucidez como estado cuja permanência seja predominante. Essa inversão da atenção pode resguardar

\footnotetext{
${ }^{14}$ CAPRARA, Andrea; FRANCO, Anamélia Lins e Silva. A relação paciente-médico: para uma humanização da prática médica. Cad. Saúde Pública [online], v. 15, n. 3, p. 647-654, p. 648, 1999. http://dx.doi. org/10.1590/S0102-311X1999000300023. Disponível em: http://www.scielo.br/scielo.php?pid=S0102 311X1999000300023\&script=sci_abstract\&tIng=pt. Acesso em: 1 jun. 2017.

${ }^{15}$ ANDERSON, Elizabeth S. op. cit., p. 199.

${ }^{16}$ Id. Ibid., p. 213.

${ }^{17}$ Id., loc. cit.

${ }^{18}$ MOUREIRA, Diogo Luna; SÁ, Maria de Fátima Freire de. Autonomia privada e vulnerabilidade: o direito civil e a diversidade democrática. In: LIMA, Taísa Macena de; MOUREIRA, Diogo Luna; SÁ, Maria Fátima Freire de (Orgs.). Autonomia e vulnerabilidade. Belo Horizonte: Arraes, 2017. p. 136-138.
} 
à prática médica maior coerência com o ordenamento jurídico vigente. Afinal, ao modificar os artigos $3^{\circ} \mathrm{e} 4^{\circ}$ do Código Civil ${ }^{19}$, o Estatuto da Pessoa com Deficiência elimina a possibilidade de interdição judicial, sobretudo na modalidade absoluta, na busca pela concreção da proporção na medida extrema de elisão de capacidade, admitindo-se a gradação dos efeitos da curatela ${ }^{20}$.

Não há consenso na psiquiatria acerca de quais transtornos admitem ou não intervalos de lucidez ${ }^{21}$. Merece destaque a postura médica recomendável, pelo regime jurídico atual, cujo ponto de partida seja a presunção de discernimento, o que repercute no campo da igualdade democrática. Logo, a construção diagnóstica e terapêutica, para a recomendação de medidas de cuidado, há de se desenhar tendo a capacidade como regra, para que todos, em maior medida, tenham assegurada a prerrogativa de exercício da autonomia privada, por meio das liberdades socialmente disponíveis, para a construção da pessoalidade, conforme o juízo de valor próprio. O Estatuto da Pessoa com Deficiência empenha-se em implementar o papel do Estado de disponibilizar as condições e garantias necessárias para o igual exercício da liberdade por todos, para que se firme a possibilidade de as pessoas escolherem quais bens lhes são úteis ou importantes ${ }^{22}$.

Vale perceber que a autora compartilha a visão de que cabe assegurar condições para o exercício de liberdades, mas que medidas nesse sentido sirvam para libertar, para permitir a inclusão da pessoa na construção democrática da igualdade, minimizando os juízos degradantes da capacidade das pessoas.

Mas as iniciativas normativas de tutela de vulnerabilidades pré-categorizam e fragilizam ou, lado outro, promovem condições de igualdade no exercício de liberdades? Alguns instrumentos normativos merecem destaque quando as atenções se voltam à relação médico-paciente. A importância da vontade do paciente envolvido no tratamento médico ganha espaço no Código de Nuremberg, promulgado em 1947, e na Declaração de Helsinque, de 1964, da Associação Médica Mundial, que tratam mais do consentimento como premissa insubstituível para utilização de seres humanos em experimentos. Em 1981, a Associação Médica Mundial afirmou, com a Declaração de Lisboa, o direito do paciente de consentir ou recusar qualquer procedimento diagnóstico ou terapêutico ${ }^{23}$. Nos Estados Unidos da América, somente no ano de 1991 foi editado o Patient Self-Determination Act ${ }^{24}$, ou estatuto da autodeterminação do paciente ${ }^{25}$.

\footnotetext{
${ }^{19}$ BRASIL. Lei n. 13.105, de 16 de março de 2015. Código de Processo Civil. Disponível em: http://www. planalto.gov.br/ccivil_03/_ato2015-2018/2015/lei/I13105.htm. Acesso em: 31 out. 2019.

${ }^{20}$ MOUREIRA, Diogo Luna; SÁ, Maria de Fátima Freire de. op. cit., p. 136-138.

${ }^{21}$ PALOMBA, Guido Arturo. Intervalos lúcidos. Saúde Mental, v. 2, n. 2, p. 37, mar./abr. 2000. Disponível em: http://www.saude-mental.net/pdf/vol2_rev2_artigo2.pdf. Acesso em: 01 jul. 2017.

${ }^{22}$ ANDERSON, Elizabeth S. op. cit., p. 124.

${ }^{23}$ TEIXEIRA, Ivan Lobato. op. cit., p. 71-72.

${ }^{24}$ UNITED STATES. Congress.Gov. R.4449 - Patient Self Determination Act of 1990. Disponível em: https://www.congress.gov/bill/101st-congress/house-bill/4449. Acesso em: 25 set. 2019.

${ }^{25}$ NAVES, Bruno Torquato de Oliveira; SÁ, Maria de Fátima Freire de. Manual de biodireito. Belo Horizonte: Del Rey, 2009. p. 84.
} 
A prática médica recebe os efeitos de uma normativa também nacional (Estatuto da Pessoa com Deficiência), influenciada pelo movimento mundial da determinação do consentimento como essencial nas atuações médicas em geral. Trata-se, de início, da Convenção para a Proteção dos Direitos do Homem e da Dignidade do Ser Humano face às Aplicações da Biologia e da Medicina (Convenção de Oviedo) ${ }^{26,27}$.

Apesar de todas essas normativas, a concretização do espaço à pessoa para que seja respeitada por seus pares em sua aptidão de decidir livremente passa, na perspectiva do igualitarismo democrático de Elizabeth Anderson, pelo tratamento médico denominado compartilhado. Nessa sistemática, a execução da ação médica é decidida em conjunto, na forma de parceria em que médico e paciente têm objetivos em comum. Nesse caso, a "inter-relação se baseia no respeito mútuo pelas competências e prerrogativas de cada um, bem como no reconhecimento da vantagem de combinar esforços para obter maiores benefícios"28.

Nesse compartilhar de decisões é que, na medida em que a responsabilidade é assumida pelas duas partes, há maior chance de concreção da igualdade para além da mera adesão ao tratamento, pois a compreensão e a convicção do paciente são construídas de modo discernido, no âmbito da liberdade decisória que pode abarcar desde a adesão até o desenho do tratamento e o profissional eleito para fazer a condução da abordagem clínica, entendida de maneira ampla. A forma de comunicação e o que se seleciona para ser informado tornam-se, assim, elementos indispensáveis para a democratização do saber do paciente, que, por conseguinte, aproxima-se mais da efetiva liberdade para exercício de seus direitos ${ }^{29}$. Portanto, para o alcance da igualdade democrática no caso de tratamento psiquiátrico, o paciente deve ter a seu dispor uma rede recursiva de possibilidades na qual lhe seja viável o exercício dialógico de sua autonomia privada.

\section{Reflexões sobre medidas de cuidado sem incapacidade para a implementação da igualdade democrática no tratamento psiquiátrico}

Constatada a necessidade da construção dialógica da decisão do paciente que busca o tratamento psiquiátrico para que seja respeitada sua aptidão de exercer as liberdades nos termos da igualdade democrática de Elizabeth Anderson, apresentam-se, a seguir, reflexões prospectivas e práticas, que podem colaborar para o

\footnotetext{
${ }^{26}$ CONSELHO DA EUROPA. Convenção para a Protecção dos Direitos do Homem e da Dignidade do Ser Humano face às Aplicações da Biologia e da Medicina. Disponível em: http://www.dhnet.org.br/direitos/ sip/euro/principaisinstrumentos/16.htm. Acesso em: 25 set. 2019.

${ }^{27}$ KHUN apud NOGUEIRA, Roberto Henrique Porto. op. cit., p. 188.

${ }^{28}$ WANNMACHER apud NOGUEIRA, Roberto Henrique Porto. op. cit., p.190.

${ }^{29} / d$., loc. cit.
} 
exercício da liberdade para além da mera adesão do tratamento, assim como para a efetivação da igualdade para além da mera dualidade.

O cotidiano psiquiátrico contempla, em geral, três fases: o acesso, o acolhimento e o acompanhamento. No que tange ao acesso, essa oportunidade não se refere somente à adequação da estrutura ou de aspectos físicos, mas também à potencialidade na forma de atender, escutar, avaliar e discriminar as demandas. Em relação ao acolhimento, demanda tanto uma ação imediata (urgência) quanto o tempo para a resposta (traçar a conduta). Assim, considerando que o acolhimento e o acompanhamento são promovidos por vários profissionais ${ }^{30}$, é de suma importância que todos se guiem pelo objetivo de promover a dialogicidade na relação médica psiquiátrica, de modo que o acompanhamento permita, com qualidade e com persistente revisitação de suas práticas, a continuidade do cuidado. Na prática, além da compreensão desse novo cenário de medidas plurais de cuidado, é mister a elaboração de protocolos operacionais que compreendam essa perspectiva compartilhada e individualizada e que permitam o registro probatório das dinâmicas cotidianas, para a proteção dos envolvidos.

Para a finalidade deste ensaio, adota-se a concepção de medidas de cuidado que abrange toda e qualquer iniciativa de tutela de direitos de personalidade ou de vulnerabilidade subjetiva. Tal vulnerabilidade é substrato para a criação de mecanismos para disponibilizar à pessoa a liberdade de assumir responsabilidade. Logo, cabe alusão à dignificação da pessoa com deficiência mental marcada pela Lei Antimanicomial, que inaugura princípios jurídicos voltados à concreção de medidas de cuidado menos incapacitantes e mais preservadoras da autonomia do paciente. Também merecem abordagem, de um lado, a curatela e a tomada de decisão apoiada, regulamentada pela teoria das incapacidades - ou, numa linguagem mais próxima do igualitarismo democrático, pela teoria das capacidades -, e, de outro lado, medidas práticas que envolvem, exemplificativamente, a prescrição racional, a definição da legitimidade do profissional na condução do processo informativo e clínico e a integração do paciente e terceiros na relação, independentemente de rigores formais ou judiciais ou mesmo de critérios tradicionais de parentesco.

Esse plexo de possibilidades talvez parta do espaço explicitado pelos instrumentos legais mencionados, quais sejam, a Lei Antimanicomial, o Decreto n. 6.949/2009 ${ }^{31}$ e o Estatuto da Pessoa com Deficiência, para instituição de medidas de cuidado sem incapacidade.

\footnotetext{
${ }^{30}$ SCHMIDT, Moema Belloni; FIGUEIREDO, Ana Cristina. Acesso, acolhimento e acompanhamento: três desafios para o cotidiano da clínica em saúde mental. Revista Latinoamericana de Psicopatia Fundamental, v. 12, n. 1, p. 130-140, 2009. Disponível em: http://www.scielo.br/pdf/rlpf/v12n1/a09v12n1. Acesso em: 10 abr. 2018.

${ }^{31}$ BRASIL. Decreto n. 6.949, de 25 de agosto de 2009. Promulga a Convenção Internacional sobre os Direitos das Pessoas com Deficiência e seu Protocolo Facultativo, assinados em Nova York, em 30 de março de 2007. Disponivel em: http://www.planalto.gov.br/ccivil_03/_ato2007-2010/2009/decreto/d6949.htm. Acesso em: 14 jun. 2018.
} 
A necessidade de tutela efetiva e garantia de direitos das pessoas com transtornos mentais deriva também de movimentos em prol de sua concretização. Têm-se como marco inicial da luta antimanicomial as ações realizadas na Itália, na década de 1980, que inspiraram a corrente brasileira denominada Reforma Psiquiátrica. Apesar das inúmeras complexidades desse movimento nacional, seja pelos atores envolvidos, seja pelas questões sociais e políticas, pode-se afirmar que, na prática, $\mathrm{o}$ objetivo é construir outros modelos para atender pacientes psiquiátricos para além do modelo assistencial hospitalocêntrico. Como resultado disso, a Lei Antimanicomial não somente tangencia a proteção e os direitos das pessoas com transtornos mentais, como também possibilita a criação de espaços para oferecer cuidados a essas pessoas, como os Centros de Atenção Psicossocial (CAPS), os Centros de Convivência e Cultura, as unidades/leitos psiquiátricos em hospitais gerais, o programa "De volta para casa”, o Programa Nacional de Avaliação do Sistema Hospitalar/Psiquiatria e os Serviços Residenciais Terapêuticos ${ }^{32}$.

Dentre eles, têm relevo os princípios regentes da relação médico-paciente no âmbito da saúde mental que espraiam conteúdos que podem ser traduzidos como algumas das medidas práticas de cuidado sem incapacidade, disponíveis ao profissional de saúde em alusão. Trata-se de medidas como a promoção, a qualquer tempo, do acesso ao melhor tratamento do sistema de saúde; a iniciativa de humanização e respeito; a preeminência da inserção familiar, laboral e comunitária; a proteção contra qualquer forma de abuso e exploração; a preservação do sigilo nas informações prestadas; a garantia da presença médica, em qualquer tempo, para esclarecimento da necessidade ou não de hospitalização involuntária; o livre acesso aos meios de comunicação disponíveis; a prestação otimizada e holística de informações a respeito de seu transtorno e de seu tratamento; a prioridade para tratamentos médicos menos invasivos; e, por fim, a valorização e busca de alternativas de tratamento em contextos comunitários de saúde mental (Lei Antimanicomial).

Tais comandos normativos inauguram um panorama que comanda o privilégio da desinstitucionalização ou, vale dizer, da institucionalização como medida residual de cuidado. Isso faz com que a internação tenda a ser mais criteriosa, menos duradoura e mais atenta às demandas particulares do paciente.

Os ganhos dessa transformação revelam algumas das medidas de cuidado independentes de incapacidade, das quais emergem prerrogativas originárias de exercício de autonomia privada, no campo de suas possibilidades reveladas pelo diagnóstico e prognóstico.

\footnotetext{
${ }^{32}$ MORAES, Viviana Carolina Oyan de; VENTURA, Carla Aparecida Arena; JORGE, Márjore Serena. Os profissionais de saúde e o exercício dos direitos humanos por portadores de transtornos mentais. Revista Eletrônica de Enfermagem, v. 15, n. 4, p. 854-861, 2013. http://dx.doi.org/10.5216/ree.v15i4.19746. Disponível em: https://www.fen.ufg.br/revista/v15/n4/v15n4a01.htm. Acesso em: 14 jun. 2018.
} 
O Estatuto da Pessoa com Deficiência, por sua vez, introduz no ordenamento jurídico pátrio as diretrizes estabelecidas pela Convenção de Nova York, também conhecida como Convenção dos Direitos da Pessoa com Deficiência ${ }^{33}$ - primeiro tratado aprovado nas duas casas legislativas brasileiras sob a égide da nova redação do artigo $5^{\circ}$, parágrafo $3^{\circ}$ da Constituição Federal de $1988^{34}$ (CF/88), assumindo, assim, status de emenda constitucional (Decreto n. 6.949/2009) -, alçando os direitos das pessoas com deficiência ao patamar de direitos fundamentais. Ao regulamentar tais comandos normativos, o documento não só apresenta institutos de tutela e efetivo tratamento digno e igual às pessoas com deficiência, mas também é causa de uma mudança drástica no regime das incapacidades. Afirma-se isso porque vários incisos dos artigos $3^{\circ}$ e $4^{\circ}$ do Código Civil foram revogados, com o objetivo de concretizar a excepcionalidade da incapacidade civil daquele que possui transtorno mental ${ }^{35}$.

Legalmente, o transtorno mental não é mais relevante, por si só, à teoria das incapacidades. Conforme a novel legislação, apenas é considerada pessoa com deficiência a pessoa com impedimento de longo prazo. Ademais, tendo a pessoa deficiência ou não em decorrência de transtorno mental, o acometimento da capacidade apenas se verifica no caso de causa transitória ou permanente que impeça a expressão da vontade.

A partir do Estatuto da Pessoa com Deficiência, a pessoa com deficiência é assim considerada quando apresenta um impedimento de longo prazo de natureza física, mental, intelectual ou sensorial, o qual, em interação com uma ou mais barreiras, pode obstruir sua participação plena e efetiva na sociedade em igualdade de condições com as demais pessoas.

O Estatuto da Pessoa com Deficiência também fixa à prática médica o múnus de atentar-se ao fato de que o regime jurídico instaurado, além de prever a alternativa da tomada de decisão apoiada (que pressupõe, exatamente, a capacidade), extirpou do ordenamento, pelo menos até a vigência do novo Código de Processo Civil, a interdição como premissa para o estabelecimento da curatela. Logo, ainda que por um curto período, pode-se afirmar que entre janeiro e março de 2016 a curatela existiu mesmo sem o pressuposto da interdição. E se a curatela parece voltar

\footnotetext{
${ }^{33}$ NAÇÕES UNIDAS. A Proteção de Pessoas Acometidas de Transtorno Mental e a Melhoria da Assistência à Saúde Mental. Disponível em: https://www2.camara.leg.br/atividade-legislativa/comissoes/comissoespermanentes/cdhm/comite-brasileiro-de-direitos-humanos-e-politica-externa/ProtPessAcomTranstment. html. Acesso em: 14 jun. 2018.

${ }^{34}$ BRASIL. Constituição da República Federativa do Brasil de 1988. Disponível em: http://www.planalto.gov. br/ccivil_03/Constituicao/Constitui\%E7ao.htm. Acesso em: 29 jun. 2017.

${ }^{35}$ REQUIÃO, Maurício. As mudanças na capacidade e a inclusão da tomada de decisão apoiada a partir do Estatuto da Pessoa com Deficiência. Revista de Direito Civil Contemporâneo, v. 6, p. 1-3, 2016. Disponível em https://s3.amazonaws.com/academia.edu.documents/44152859/RTDoc_16-3-24_8_39_PM.p df?AWSAccessKeyld=AKIAIWOWYYGZ2Y53UL3A\&Expires=1529014989\&Signature=YGAb4OPhlott4A rDTX8\%2FBEIc5lo\%3D\&response-content-disposition=inline\%3B\%20filename\%3DAs_mudancas_na_ capacidade_e_a_inclusao_d.pdf. Acesso em 14 jun. 2018.
} 
a depender de interdição para sua constituição, fato é que o Estatuto da Pessoa com Deficiência desperta para a necessidade de as comunidades médica e jurídica prepararem-se para o reconhecimento e a prática de medidas de cuidado plurais e impassíveis de predefinição, independentemente de incapacidade civil relativa. Nesse rumo, a tomada de decisão apoiada, por exemplo, é apenas uma alternativa.

Portanto, seja pelo espaço gerado pelo Estatuto da Pessoa com Deficiência, seja pelo arsenal normativo principiológico ${ }^{36}$ de enfoque específico, cabe reportar a noção de medidas de cuidado sem incapacidade. Tal noção refere-se tanto às concepções trazidas pela Lei n. 10.216/2001, que trata sobre a proteção e os direitos das pessoas com transtornos mentais e redireciona o modelo assistencial em saúde mental, quanto à dignidade da pessoa humana e aos direitos da personalidade, previstos nos artigos 11 a 21 do Código Civil. Os direitos de personalidade têm como principais características a generalidade, a extrapatrimonialidade, $\mathrm{o}$ caráter absoluto, a inalienabilidade, a imprescritibilidade, a intransmissibilidade e, por terem status de direito fundamental, o fato de não estarem limitados a um rol taxativamente estabelecido.

Este artigo estabelece a tomada de decisão apoiada como o processo pelo qual a pessoa com deficiência escolhe, no mínimo, duas pessoas de sua confiança para lhe dar apoio na tomada de decisão sobre atos da vida civil. A função desses apoiadores é auxiliar com os elementos e informações necessários para que a pessoa com discernimento reduzido possa exercer sua autonomia.

Tais previsões são extremamente importantes, pois, mesmo que com a finalidade de proteção, medidas extremas de incapacidade podem resultar em barreiras para o acesso a direitos fundamentais, a partir do desrespeito ao próprio direito à igualdade e à liberdade. Assim, a previsão de medida de proteção e de cuidado que prescinda de declaração de incapacidade concretiza feições de uma pessoa mais próxima da edificação de sua dignidade ${ }^{37}$.

É íntima, portanto, a relação entre dignidade da pessoa humana e direitos de igualdade e liberdade.

Pela dinâmica dessa liberdade associada à garantia de igualdade é que se faz possível falar em vida digna. Nesse contexto, a dignidade expressa-se como a síntese entre a liberdade e a igualdade, ambas fundamentos da democracia. Em favor da igualdade, é

${ }^{36}$ TEPEDINO, Gustavo. A tutela da personalidade no ordenamento civil-constitucional brasileiro. p. 10. Disponível em: https://www.academia.edu/31740015/A_tutela_da_personalidade_no_ordenamento_ civil-constitucional_brasileiro?auto=download. Acesso em: 15 jul. 2017.

${ }^{37}$ MENEZES, Joyceane Bezerra de. Tomada de decisão apoiada: instrumento de apoio ao exercício da capacidade civil da pessoa com deficiência instituído pela lei brasileira de inclusão. Revista Brasileira de Direito Civil, Rio de Janeiro, v. 9, p. 36, jul./set. 2016. Disponível em: https://www.ibdcivil.org.br/.../ rbdcivil_vol_9_03_tomada-de-decisueo-apoiada.pdf. Acesso em: 15 jul. 2017. 
possível frear a liberdade, fazendo emergir uma dignidade social e objetiva, de caráter heterônomo; mas, para evitar a imposição autoritária dessa dignidade sobre os valores de liberdade e autonomia das pessoas, a dignidade também pode expressar uma dimensão subjetiva que conduz à autodeterminação, notadamente no plano das questões existenciais ${ }^{38}$.

A necessidade de promover a emancipação ou o desocultamento da pessoa, por meio da disponibilização de condições amplas, informativas e materiais, para exercício de liberdades não pode resvalar em intervenção na própria manifestação, ou seja, no exercício da liberdade para a assunção de responsabilidades.

Em tentativa de refletir sobre aspectos aplicados de medidas de cuidado sem incapacidade, nota-se inicialmente que, além daquelas medidas previstas na Lei Antimanicomial, a tomada de decisão apoiada pode ser cabível e até mesmo sugerida pelo médico psiquiatra em sua relação com o paciente. A presença de pessoas da confiança do paciente para auxiliá-lo na escolha do tratamento é uma medida de cuidado que se impõe para a construção da dialogicidade do tratamento. E mais: se medidas de cuidado não se restringem às previstas em lei, é certo que, como medida de cuidado, o médico está autorizado e encorajado a admitir terceiros que não sejam apoiadores judiciais formais em sua relação jurídica com o paciente, a seu pedido e por sua escolha e indicação. Todas essas são possibilidades à prática médica, para a consonância com o cenário instituído pelas transformações havidas no sistema jurídico das capacidades.

Medida de cuidado sempre recomendada pelos códigos deontológicos é a informação. Essa informação, na perspectiva pluralizante aqui pretendida, deve ir além das características do transtorno ou da conduta terapêutica. Pode incluir, ainda, dados acerca da formação técnica do profissional, para que o paciente decida se o considera legítimo para a condução do processo clínico. Acredita-se, nesse tocante, que a diferença entre especialização médica (treinamento rigoroso em serviço) e mera pós-graduação em sentido lato, se devidamente elucidada, pode determinar a opção do paciente pela eventual atribuição de legitimidade ao médico para a condução do processo formativo de convicções e de abordagens. Significa que, em razão do dever de informação, é defensável o dever do médico de apresentar-se, profissionalmente, com dados sobre sua formação técnica e seu universo de conhecimento, para que, com base nesse aparato, possa o paciente manifestar-se, já ciente de que, mesmo de posse das informações em linguagem clara, é influenciado por um perito que merece sua confiança ${ }^{39}$. Essa reflexão é

\footnotetext{
${ }^{38}$ MENEZES, Joyceane Bezerra de. op. cit., p. 36.

${ }^{39}$ NOGUEIRA, Roberto Henrique Porto. op. cit., p. 198.
} 
bastante relevante, em vista da existência de heterogeneidade no ensino da Psiquiatria nas escolas médicas brasileiras ${ }^{40}$.

Também pode ter destaque, como medida de cuidado, a demonstração de lastro para o apontamento ou sugestão de terapia específica, principalmente quando diante de prescrição offlabel, ou seja, de recomendação que extrapola o uso aprovado pelo órgão regulatório e, portanto, alheio à bula. Cabe ao profissional, como medida de cuidado, reavaliar tratamentos ou explicitar as bases de tratamento prescrito, conforme ditames de prescrição racional, a serem conhecidos e compreendidos pelo paciente.

O médico pode colocar-se no lugar do paciente e prestar as informações que, apesar de lhe serem óbvias, geralmente não são de conhecimento daquele que busca tratamento. Esse é o poder da empatia: não só o de informar, mas o de abrir um canal de conhecimento mútuo entre os sujeitos envolvidos ${ }^{41}$. Assumir essa posição é saltar do simples diálogo para o dialógico, na medida em que o dialógico só pode ocorrer em ambiente de reciprocidade, respeito e consideração entre um e o outro ${ }^{42}$.

Uma possibilidade de cuidado, obtido pela via da transparência e acesso à informação, considerando o momento atual e as perspectivas de investimento no setor de $e$-Health (tecnologia em informática utilizada em prol da melhoria de serviços de saúde), é a disponibilização de aplicativos que facilitem o fluxo de dados entre médico e paciente.

Outro horizonte viável, nesse sentido, é a constante reformulação, pelos cursos de medicina no Brasil, da disciplina de Semiologia, expressão derivada do grego que significa "estudo dos sinais". Esse é o campo da patologia geral no qual se aprofunda a análise dos sinais e sintomas das enfermidades, com o objetivo de ensinar a técnica adequada para apreender e apurar o que o paciente apresenta de patológico, por meio da captação sensorial do médico via audição, olfato e tato ${ }^{43}$.

Apesar de já existir tal disciplina que trata da importância de o médico comunicar e saber interpretar as ações do paciente, é mister que se intensifique a abordagem pedagógica com foco no paciente, e não somente no transtorno. Esse é

${ }^{40} \mathrm{~A}$ assertiva apoia-se em pesquisa realizada em 119 escolas de medicina do Brasil no ano de 2009, ADAD, Miguel Abib; AGUIAR, Rogério Wolf de; BELOTTO, Carolina; CORAL, Cláudia Viña, BRASIL, Marco Antônio; CATALDO NETO, Alfredo; PITTA, José Cássio do Nascimento; RAMOS, Fernanda Lia de Paula; SELBACH, Camila Ruschel; SIMONAGGIO, Patrícia Magali. Panorama nacional do ensino da psiquiatria nas escolas médicas brasileiras. Revista de Psiquiatria, Porto Alegre, v. 33, n. 1, p. 8, 2011. http://dx.doi.org/10.1590/S010181082011005000006. Disponível em: http://www.scielo.br/pdf/rprs/v33n1/1144.pdf. Acesso em: 2 jul. 2017.

${ }^{41}$ SHALF, Saul. Relacionamento médico-paciente. Revista Brasileira da Reumatologia, São Paulo, v. 43, n. 4, p. 238, jul./ago. 2003. http://dx.doi.org/10.1590/S0482-50042003000400006. Disponível em: http:// www.scielo.br/scielo.php?script=sci_arttext\&pid=S0482-50042003000400006. Acesso em: 2 jul. 2017.

${ }^{42}$ BUBER, M. Do diálogo e do dialógico. São Paulo: Perspectiva, 1982. p. 40-43.

${ }^{43}$ MIDÃO, Claudia M. de Vasconcellos; MORENO, Lidia Ruiz. O Ensino da Semiologia nas Escolas Médicas do Estado do Rio de Janeiro. Revista Brasileira De Educação Médica, Rio de Janeiro, v. 3, n. 43, p. 398, 2010. http://dx.doi.org/10.1590/S0100-55022010000300009. Disponível em: http://www.scielo.br/ pdf/rbem/v34n3/09.pdf. Acesso em: 23 jul. 2017. 
um dos grandes desafios para o ensino da medicina para o futuro: contribuir para que a relação médico-paciente se implemente de forma verdadeiramente dialógica, para além do estudo biomédico da semiologia ${ }^{44}$.

Desse modo, o estudo da semiologia e da comunicação voltado à concretização da relação dialógica pode contribuir para viabilizar os espaços de liberdade aos quais o paciente faz jus como pessoa, de maneira que participe das decisões acerca de sua própria saúde ao invés de portar-se como mero espectador. Assim, "mesmo considerando que não é o currículo que implica o cumprimento de determinados objetivos de aprendizagem, politicamente ele pode favorecê-los ou inviabilizá-los totalmente" ${ }^{35}$.

Entre todas essas ações que contribuem para a construção relação dialógica, destaca-se a promoção da inclusão, pois, ao expor sua formação e linhas de atuação, o psiquiatra demonstra na prática sua predisposição de não apenas lançar diagnósticos e termos técnicos. Evidencia-se, ainda, a postura de ser empático, pois, ao se colocar em análise para o paciente, o psiquiatra elimina a suposta posição de superioridade e contribui para o empoderamento do paciente para fazer sua escolha ${ }^{46}$.

Por fim, vale ressaltar que a posição de vulnerabilidade pode ser ocupada, inclusive, pelo psiquiatra, de maneira que os espaços de liberdade para a efetiva igualdade devem ser-lhe, do mesmo modo, assegurados. Significa dizer que deveres de colaboração e informação, dentre outros, são recíprocos, apesar de poderem sofrer modulação no que toca à intensidade em razão da eventual necessidade de ações voltadas à promoção da igualdade, rumo ao potencial exercício de liberdades e à assunção de responsabilidades.

Portanto, as medidas de cuidado apontadas podem ser instrumentos viáveis para a concretização de uma relação médica dialógica, devendo ser constante a reflexão sobre outras iniciativas de proteção, independentemente de incapacidade, criadas e praticadas conforme as necessidades e peculiaridades de cada pessoa. A prática médica, atenta a tais oportunidades, pode municiar-se de protocolos operacionais que amparem a perspectiva jurídica das capacidades dos pacientes com transtornos mentais e respectivas medidas de cuidado sem incapacidade, bem como que protejam a própria dinâmica profissional, no que se refere à prova de que os esforços possíveis foram implementados por parte do médico.

\footnotetext{
${ }^{44}$ RIBEIRO, Maria Mônica Freitas; AMARAL, Carlos Faria Santos. Medicina centrada no paciente e ensino médico: a importância do cuidado com a pessoa e o poder médico. Rev. bras. educ. med. [online], Rio de Janeiro, v. 3, n. 43, p. 96, 2008. http://dx.doi.org/10.1590/S0100-55022008000100012. Disponível em: http://www.scielo.br/pdf/rbem/v34n3/09.pdf. Acesso em: 23 jul. 2017.

${ }^{45}$ Id., loc. cit.

${ }^{46}$ MARTUCELLI, Fátima Aparecida Gomes. Presença, escuta e compreensão integrativa: um olhar dialógico sobre a relação médico-paciente. 2011. 76 f. Dissertação (Mestrado) - Pontifícia Universidade Católica de São Paulo. Programa de Pós-Graduação em Psicologia, São Paulo, 2011. p. 65.
} 


\section{Considerações finais}

A partir das noções de igualdade democrática trabalhadas por Elizabeth Anderson, conclui-se que a proteção dos sujeitos fragilizados no sistema deve ser promovida. A identificação dessa fragilidade, contudo, não deve ter como escopo a inferiorização, mas sim ter o pressuposto de que essas pessoas são iguais às demais e, por isso, cabe privilegiar, reforçar e criar meios para a emersão de sua volição, ainda que inferida, quanto à medida considerada adequada como tratamento psiquiátrico.

Na busca pela concretização do tratamento conforme a igualdade na relação médico-paciente é que se propõem medidas concretas a serem implementadas no cotidiano da prática médica psiquiátrica, tais como o uso das medidas de cuidado independentemente da decretação de incapacidade.

Refere-se, precisamente, aos deveres e aos princípios oriundos do panorama transformado das relações médico-paciente na Psiquiatria. Em especial, cabe lançar luz às contribuições da Lei Antimanicomial e do Estatuto da Pessoa com Deficiência. Desse cenário de busca pelo afastamento de juízos degradantes da pessoa, tais medidas, necessariamente plurais em razão dos fins aos quais se propõem, revelam a perspectiva de esforço para a ampliação da informação dada ao paciente pelo médico. A prática médica, ciente do novo contexto, pode valer-se dessas possibilidades para estabelecer a implementação, o controle e a prova de cuidados mais dialógicos, o que pode, inclusive, ser objeto de formação acadêmico-profissional.

Percebe-se também que, apesar das previsões normativas em prol da autonomia do paciente e do direito à informação que delas decorre, restam ainda pontos a serem discutidos a respeito da igualdade e da liberdade para a efetiva implementação da pessoalidade do paciente. A análise dessa perspectiva torna-se importante principalmente na psiquiatria, em que a fragilidade do paciente tende a comprometer, em alguma medida, seu discernimento, sem descartar o eventual incremento da vulnerabilidade do próprio profissional médico, devido à dificuldade de registro de atuação em conformidade com o novo cenário jurídico.

A partir disso, buscam-se a liberdade e a igualdade para além da mera adesão ao tratamento, apesar de não haver a pretensão de se rejeitar, de plano, o recurso à tutela da vulnerabilidade em suas perspectivas pré-categorizantes, sobretudo quando inexistentes recursos ou mecanismos mais capazes de efetivação da inclusão e do reconhecimento de sujeitos e seus direitos. O objetivo é que se alcancem horizontes menos estereotipantes e categorizantes, que poderão, no futuro, ser suficientes à promoção da igualdade aqui tida por democrática.

Essa ideia afasta a intervenção que não permite que o sujeito exerça poder de influência em uma ação realizada para protegê-lo. Esses juízos degradantes podem ofender diretamente a dignidade, pois tendem a mitigar a autonomia e a prejudicar a construção da pessoalidade. 
Nessa linha de intelecção, ganham espaço institutos cujo objetivo seja promover o exercício autônomo de direitos, como as medidas de cuidado, mesmo que não atreladas à incapacidade. Trata-se da ênfase nas capacidades civis e na tomada de decisão apoiada trazida pelo Estatuto da Pessoa com Deficiência, ao lado das medidas propostas pela Lei Antimanicomial, tais como acesso a melhor tratamento do sistema de saúde; iniciativa de humanização e respeito; preeminência da inserção familiar, laboral e comunitária; proteção contra qualquer forma de abuso e exploração; preservação do sigilo nas informações prestadas; garantia da presença médica, em qualquer tempo, para esclarecimento da necessidade ou não de hospitalização involuntária; livre acesso aos meios de comunicação disponíveis; prestação otimizada e holística de informações a respeito de seu transtorno e de seu tratamento; prioridade para tratamentos médicos menos invasivos; e, por fim, valorização e busca por alternativas de tratamento em contextos comunitários de saúde mental.

Nessa esteira, se, desde o início, foi recortada para uma futura iniciativa investigativa a proposta de relacionar medidas de cuidado sem incapacidade às dificuldades específicas dos diferentes comprometimentos mentais e ao próprio estigma existente em relação às pessoas com transtornos, conclui-se que o trabalho obtém êxito em evidenciar o uso de tecnologias e mecanismos jurídicos para a integração da pessoa na relação médico-paciente. Assim, descortinam-se alertas e possibilidades à prática médica psiquiátrica rumo à percepção de uma nova realidade das capacidades civis e à formatação de protocolos de atuação médica suficientes ao controle, ao registro e à prova de atendimento aos parâmetros jurídicos.

\section{Referências}

ADAD, Miguel Abib; AGUIAR, Rogério Wolf de; BELOTTO, Carolina; CORAL, Cláudia Viña, BRASIL, Marco Antônio; CATALDO NETO, Alfredo; PITTA, José Cássio do Nascimento; RAMOS, Fernanda Lia de Paula; SELBACH, Camila Ruschel; SIMONAGGIO, Patrícia Magali. Panorama nacional do ensino da psiquiatria nas escolas médicas brasileiras. Revista de Psiquiatria, Porto Alegre, v. 33, n. 1, p. 8-13, 2011. http://dx.doi.org/10.1590/S0101-81082011005000006. Disponível em: http://www.scielo.br/pdf/rprs/v33n1/1144.pdf. Acesso em: 2 jul. 2017.

ANDERSON, Elizabeth S. Qual é o sentido da igualdade? Revista Brasileira de Ciência Política, Brasília-DF, n. 15, p. 163-227, set./dez. 2014. http://dx.doi.org/10.1590/0103-335220141507. Disponível em: http://periodicos.unb.br/index.php/rbcp/article/view/13080. Acesso em: 13 jun. 2017.

BUBER, M. Do diálogo e do dialógico. São Paulo: Perspectiva, 1982.

CAPRARA, Andrea; FRANCO, Anamélia Lins e Silva. A relação paciente-médico: para uma humanização da prática médica. Cad. Saúde Pública [online], v. 15, n. 3, p. 647-654, p. 647-654, 1999. http://dx.doi.org/10.1590/S0102-311X1999000300023. Disponível em: http://www. scielo.br/scielo.php?pid=S0102-311X1999000300023\&script=sci_abstract\&tlng=pt. Acesso em: 1 jun. 2017. 
CONSELHO DA EUROPA. Convenção para a Protecção dos Direitos do Homem e da Dignidade do Ser Humano face às Aplicações da Biologia e da Medicina. Disponível em: http://www.dhnet. org.br/direitos/sip/euro/principaisinstrumentos/16.htm. Acesso em: 25 set. 2019.

DE VITA, Álvaro. Liberalismo igualitário e multiculturalismo. Lua Nova, São Paulo, n. 55-56, p. 5-27, 2002. http://dx.doi.org/10.1590/S0102-64452002000100001. Disponível em: http:// www.scielo.br/scielo.php?script=sci_arttext\&pid=S0102-64452002000100001\&lng=en\&nr $\mathrm{m}=$ iso. Acesso em: 02 jun. 2017.

MARTUCELLI, Fátima Aparecida Gomes. Presença, escuta e compreensão integrativa: um olhar dialógico sobre a relação médico-paciente. 2011. 76 f. Dissertação (Mestrado) Pontifícia Universidade Católica de São Paulo. Programa de Pós-Graduação em Psicologia, São Paulo, 2011.

MENEZES, Joyceane Bezerra de. Tomada de decisão apoiada: instrumento de apoio ao exercício da capacidade civil da pessoa com deficiência instituído pela lei brasileira de inclusão. Revista Brasileira de Direito Civil, Rio de Janeiro, v. 9, p. 31-57, jul./set. 2016. Disponível em: https://www.ibdcivil.org.br/.../rbdcivil_vol_9_03_tomada-de-decisueo-apoiada.pdf. Acesso em: 15 jul. 2017.

MIDÃO, Claudia M. de Vasconcellos; MORENO, Lidia Ruiz. O Ensino da Semiologia nas Escolas Médicas do Estado do Rio de Janeiro. Revista Brasileira De Educação Médica, Rio de Janeiro, v. 3, n. 43, p. 397-405, 2010. http://dx.doi.org/10.1590/S0100-55022010000300009. Disponível em: http://www.scielo.br/pdf/rbem/v34n3/09.pdf. Acesso em: 23 jul. 2017.

MORAES, Viviana Carolina Oyan de; VENTURA, Carla Aparecida Arena; JORGE, Márjore Serena. Os profissionais de saúde e o exercício dos direitos humanos por portadores de transtornos mentais. Revista Eletrônica de Enfermagem, v. 15, n. 4, p. 854-861, 2013. http:// dx.doi.org/10.5216/ree.v15i4.19746. Disponível em: https://www.fen.ufg.br/revista/v15/n4/ v15n4a01.htm. Acesso em: 14 jun. 2018.

MOUREIRA, Diogo Luna; SÁ, Maria de Fátima Freire de. Autonomia privada e vulnerabilidade: o direito civil e a diversidade democrática. In: LIMA, Taísa Macena de; MOUREIRA, Diogo Luna; SÁ, Maria Fátima Freire de (Orgs.). Autonomia e vulnerabilidade. Belo Horizonte: Arraes, 2017.

NAÇÕES UNIDAS. A Proteção de Pessoas Acometidas de Transtorno Mental e a Melhoria da Assistência à Saúde Mental. Disponível em: https://www2.camara.leg.br/atividade-legislativa/ comissoes/comissoes-permanentes/cdhm/comite-brasileiro-de-direitos-humanos-e-politicaexterna/ProtPessAcomTranstment.html. Acesso em: 14 jun. 2018.

NAVES, Bruno Torquato de Oliveira; SÁ, Maria de Fátima Freire de. Manual de biodireito. Belo Horizonte: Del Rey, 2009.

NOGUEIRA, Roberto Henrique Porto. Prescrição off label de medicamentos, ilicitude e responsabilidade civil do médico. Belo Horizonte: Ed. PUC Minas, 2017. 
PALOMBA, Guido Arturo. Intervalos lúcidos. Saúde Mental, v. 2, n. 2, p. 37-41, mar./abr. 2000. Disponível em: http://www.saude-mental.net/pdf/vol2_rev2_artigo2.pdf. Acesso em: 01 jul. 2017.

REQUIÃO, Maurício. As mudanças na capacidade e a inclusão da tomada de decisão apoiada a partir do Estatuto da Pessoa com Deficiência. Revista de Direito Civil Contemporâneo, v. 6, p. 1-17, 2016. Disponível em https://s3.amazonaws.com/academia.edu.documents/44152859/ RTDoc_16-3-24_8_39_PM.pdf?AWSAccessKeyId=AKIAIWOWYYGZ2Y53UL3A\&Expire $s=1529014989 \&$ Signature $=$ YGAb4OPhIott4ArDTX8\%2FBEIc5Io\%3D\&response-contentdisposition=inline\%3B\%20filename\%3DAs_mudancas_na_capacidade_e_a_inclusao_d. pdf. Acesso em 14 jun. 2018.

RIBEIRO, Maria Mônica Freitas; AMARAL, Carlos Faria Santos. Medicina centrada no paciente e ensino médico: a importância do cuidado com a pessoa e o poder médico. Rev. bras. educ. med. [online], Rio de Janeiro, v. 3, n. 43, p. 90-97, 2008. http://dx.doi.org/10.1590/ S0100-55022008000100012. Disponível em: http://www.scielo.br/pdf/rbem/v34n3/09.pdf. Acesso em: 23 jul. 2017.

SCHMIDT, Moema Belloni; FIGUEIREDO, Ana Cristina. Acesso, acolhimento e acompanhamento: três desafios para o cotidiano da clínica em saúde mental. Revista Latinoamericana de Psicopatia Fundamental, v. 12, n. 1, p. 130-140, 2009. Disponível em: http://www.scielo.br/pdf/rlpf/v12n1/a09v12n1. Acesso em: 10 abr. 2018.

SHALF, Saul. Relacionamento médico-paciente. Revista Brasileira da Reumatologia, São Paulo, v. 43, n. 4, p. 238-239, jul./ago. 2003. http://dx.doi.org/10.1590/S048250042003000400006. Disponível em: http://www.scielo.br/scielo.php?script=sci_arttext\&p $\mathrm{id}=$ S0482-50042003000400006. Acesso em: 2 jul. 2017.

STANCIOLI, Brunello Souza. Relação Jurídica médico-paciente. Belo Horizonte: Del Rey, 2004.

TEIXEIRA, Ivan Lobato. Capacidade e consentimento na relação médico/paciente. 2009. $210 \mathrm{f}$. Dissertação (Mestrado) - Programa de Pós-Graduação em Direito da Faculdade de Direito da Universidade de São Paulo, São Paulo, 2012. Disponível em: http://www.teses.usp.br/teses/ disponíveis/2/2131/tde-07052010-085547/. Acesso em: 13 out. 2012.

TEPEDINO, Gustavo. A tutela da personalidade no ordenamento civil-constitucional brasileiro. Disponível em: https://www.academia.edu/31740015/A_tutela_da_personalidade_no_ ordenamento_civil-constitucional_brasileiro?auto=download. Acesso em: 15 jul. 2017.

UNITED STATES. Congress.Gov. R.4449 - Patient Self Determination Act of 1990. Disponível em: https://www.congress.gov/bill/101st-congress/house-bill/4449. Acesso em: 25 set. 2019. 
Silva L. B. R., Nogueira R. H. P.

Leila Bitencourt Reis da Silva - Doutoranda na Pós-Graduação strictu sensu em Direito da Universidade Federal de Minas Gerais (UFMG). Mestrado na Pós-Graduação stricto sensu em Direito da Universidade Federal de Ouro Preto (UFOP); especialização em Direito Privado pela Pontifícia Universidade Católica de Minas Gerais (PUC-MINAS). Pesquisadora do Núcleo Novos Direitos Privados e colaboradora do Centro de Mediação e Cidadania da UFOP. Ouro Preto/MG, Brasil. E-mail: leilareis091@gmail.com

Roberto Henrique Pôrto Nogueira - Doutorado em Direito Privado pela Pontifícia Universidade Católica de Minas Gerais (PUC-MINAS); especialização em Direito Tributário pela Faculdade Milton Campos. Pesquisador do Núcleo Novos Direitos Privados e coordenador do Centro de Mediação e Cidadania da Universidade Federal de Ouro Preto (UFOP). Professor adjunto da Graduação e Pós-Graduação stricto sensu em Direito da UFOP. 